Article

\title{
Atmospheric Contamination of Coastal Cities by the Exhaust Emissions of Docked Marine Vessels: The Case of Tromsø
}

\author{
Asier Zubiaga ${ }^{1, * \mathbb{D}}$, Synne Madsen ${ }^{2}$, Hassan Khawaja ${ }^{2, *} \mathbb{D}$ and Gernot Boiger ${ }^{1}$ (D) \\ 1 Institute Computational Physics, Zurich University of Applied Science, Technikumstrasse 9, \\ CH-8401 Winterthur, Switzerland; gernot.boiger@zhaw.ch \\ 2 Department of Automation and Process Engineering, The Arctic University of Norway, N-9037 Tromsø, \\ Norway; sma099@post.uit.no \\ * Correspondence: asier.zubiaga@zhaw.ch or asier.zubiaga@gmail.com (A.Z.); hassan.a.khawaja@uit.no (H.K.)
}

check for

updates

Citation: Zubiaga, A.; Madsen, S.; Khawaja, H.; Boiger, G. Atmospheric Contamination of Coastal Cities by the Exhaust Emissions of Docked Marine Vessels: The Case of Tromsø. Environments 2021, 8, 88. https:/ / doi.org/10.3390/environments8090088

Academic Editors: Francesco

Petracchini, Valerio Paolini and Valeria Rizza

Received: 2 August 2021

Accepted: 29 August 2021

Published: 3 September 2021

Publisher's Note: MDPI stays neutral with regard to jurisdictional claims in published maps and institutional affiliations.

Copyright: (c) 2021 by the authors. Licensee MDPI, Basel, Switzerland. This article is an open access article distributed under the terms and conditions of the Creative Commons Attribution (CC BY) license (https:// creativecommons.org/licenses/by/ $4.0 /)$.

\begin{abstract}
Docked ships are a source of contamination for the city while they keep their engine working. Plume emissions from large boats can carry a number of pollutants to nearby cities causing a detrimental effect on the life quality and health of local citizens and ecosystems. A computational fluid dynamics model of the harbour area of Tromsø has been built in order to model the deposition of $\mathrm{CO}_{2}$ gas emitted by docked vessels within the city. The ground level distribution of the emitted gas has been obtained and the influence of the wind speed and direction, vessel chimney height, ambient temperature and exhaust gas temperature have been studied. The deposition range is found to be the largest when the wind speed is low. At high wind speeds, the deposition of pollutants along the wind direction is enhanced and spots of high pollutant concentration can be created. The simulation model is intended for the detailed study of the contamination in cities near the coast or an industrial pollutant source of any type of gas pollutant and can easily be extended for the study of particulate matter.
\end{abstract}

Keywords: computational fluid dynamics; OpenFOAM; docked vessel; gas pollutants

\section{Introduction}

Plume emissions from industrial activities and large boats can carry a number of pollutants to nearby cities causing a detrimental effect on the life quality and health of local citizens and ecosystems [1,2]. The main pollutants are waste products of combustion processes, mainly carbon monoxide (CO), nitrogen and sulfur oxides $\left(\mathrm{NO}_{x}, \mathrm{SO}_{x}\right)$ in gas phase, as well as solid particulate matter and black carbon. They are suspended in the released exhaust gases. Carbon dioxide $\left(\mathrm{CO}_{2}\right)$ is the main by-product in exhaust plumes. While it does not have a direct health effect, its influence on climate warming is well known.

Docked ships are a source of contamination for a city while they keep their engine working [3-6]. Emission from manoeuvring ships can also be substantially high. However, docked vessels become an important source of contamination when they must keep their engines working to maintain their vital functions while in the harbour. The deposited fraction of particulates and gas traces at street level is an indicator of the air pollution in the city. The exhaust gas and the suspended particulates are transported by the wind over the habited areas $[7,8]$. The interplay between the wind and the local orography will determine the transport distance and the fraction reaching the ground level $[9,10]$.

The pollutants can be divided into two types: Gas molecules and larger particulate matter [11]. Each has different transport mechanisms. While gas pollutants are transported as part of the main fluid, solid particles are subject to drag by the fluid and they tend to suspend by gravity. Both types of particles are emitted from an exhaust at a relatively large concentration and they mix and dilute thanks to buoyancy effects and lateral diffusion. This last effect is especially relevant in increasing the diffusion range of the gas phase 
pollutants. On the other hand, particulate matter is mainly driven by buoyancy and the drag forces. This has an effect on their distribution close to the emission point. An accurate assessment of the contaminant distributions can be achieved using real scale atmospheric simulations including the local terrain orography and building distribution. A real scale model should consider as input parameters the atmospheric condition (temperature, wind and pressure), the topography of the studied area and the position and size of the main buildings. To study the contamination coming from docked vessels, the height of the exhaust and the temperature of the plume must also be considered.

In this work, we use computational fluid dynamics simulations of flowing air on a topographic model of the sea side in the city of Tromsø. The emission from docked vessels and the interplay between the general wind flow and the exhaust gas have been modelled in detail. We expect that this result will help to asses the effect of docked vessels in the contamination of the city of Tromsø and to introduce mitigation measures. Special attention has been given to the dispersion of a trace gas, $\mathrm{CO}_{2}$ in this study, that is representative for the dispersion of pollutants emitted by the vessel and their distribution at street level. For that purpose, the emission from a vessel situated in the Tromsø harbour has been considered. The parameters that influence the final distribution of the emitted pollutants have been varied. Special attention has been given to the influence of the wind speed and direction, the ambient and outflowing gas temperatures and the chimney height. In Section 2, the used computational technique are described. The main results are given in Section 3 and the most important results are discussed in Section 4. Finally, the main conclusions are summarized in Section 5.

\section{Materials and Methods}

The study of the pollutant distribution is based on a computational fluid dynamics (CFD) simulation of the exhaust gas distribution over and within the city of Tromsø. The simulation domain is constructed using a topographic model of the city harbour area. The coordinates of the topography were obtained from satellite data [12], which allows to download the longitude, latitude and altitude along selected paths. The longitude and the latitude from the raw data have to be converted to Cartesian points $(x, y, z)$ and written in comma separated value (CSV) format. The position data is imported into a computer aided design software [13]. The positioning and size of the largest buildings in the harbour area were defined in the same way as the topography of the terrain and incorporated into the ground model. The structures of concern were storage facilities of the port, a high school, an office building, part of the hospital and a prison. Finally, three cylinders in the harbour area, representing the chimneys of a docked vessel, were added. The collection of points was then converted into a 2D model of the terrain within Solidworks. The resulting ground topographic model has a diameter of $800 \mathrm{~m}$, shown in Figure 1, and describes the main buildings near the harbour area together with the main features of the terrain. The 3D geometry is completed by extruding a cylinder on top of the terrain model with a total height above sea level of $300 \mathrm{~m}$. The height of the ground model ranges between $0 \mathrm{~m}$ at the sea and $34 \mathrm{~m}$ at the highest point. The typical height of the buildings ranges between $5 \mathrm{~m}$ and $10 \mathrm{~m}$. An air column of up to $300 \mathrm{~m}$ was added for the fluid simulation. The resulting simulation domain has a cylindrical shape truncated below by the non-flat terrain.

Several chimney heights were considered: $5 \mathrm{~m}, 10 \mathrm{~m}$ and $20 \mathrm{~m}$. For the temperatures of the emitted gas at the exit of the chimney values between $10{ }^{\circ} \mathrm{C}$ and $200{ }^{\circ} \mathrm{C}$ were used. The exit speed of the exhaust gas, $25 \mathrm{~m} / \mathrm{s}$, and the fraction of emitted $\mathrm{CO}_{2}, 40 \%$, were set at typical values for large vessels. The environment temperature varied between $0{ }^{\circ} \mathrm{C}$ and $20^{\circ} \mathrm{C}$.

The 3D model was meshed using ANSYS Workbench [14] to a $1.3 \times 10^{6}$ tetrahedral cells mesh. The boundaries were meshed using a triangular mesh and they were divided into four regions: Top boundary, side boundaries, ground and exhaust of the chimney. The exhaust region will be used to define the plume inlet conditions. The side boundaries will accommodate the inlet/outlet conditions of the wind and the atmospheric boundary layer 
conditions. The ground will be distinctive in that it will require no-slip and wall conditions for the simulated quantities. Finally, the top boundary will be used to ensure a smooth vertical distribution of temperature and pressure. The mesh was refined around the main features of the terrain. The size of the mesh elements and the degree of refinement close to the main features are illustrated in Figure 2.

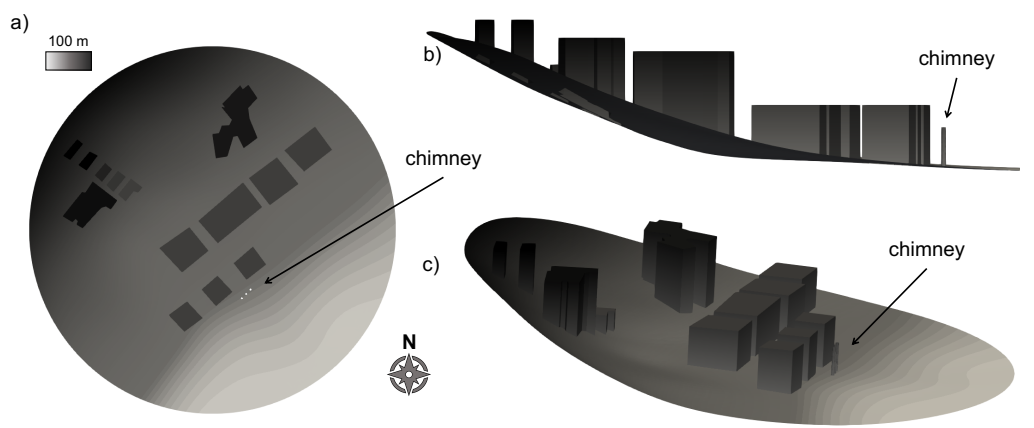

Figure 1. Topographic model of the harbour area of Tromsø. The (a) vertical, (b) lateral and (c) oblique view of the topographic model is shown. The vertical scale has been magnified $(\times 5)$ for clarity.

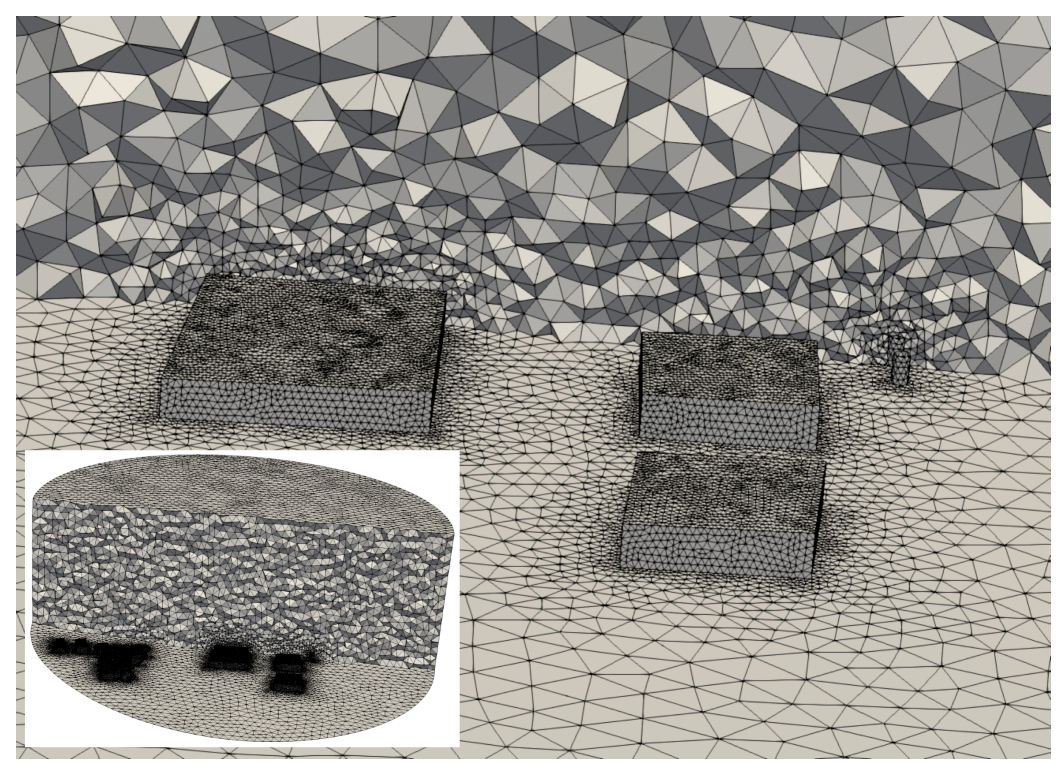

Figure 2. Tetrahedral mesh. Detail of the tetrahedral mesh used for the CFD simulation around the main features of the terrain. The inset shows a clip of the mesh along a plane extending along the north-west $(-1,1,0)$ direction.

\subsection{Computational Fluid Dynamics}

In CFD the air column is described with the Navier-Stokes equation with the gravitation $\vec{g}$ as an external force

$$
\frac{\partial \vec{u}}{\partial t}+(\vec{u} \cdot \vec{\nabla}) \vec{u}=v \nabla^{2} \vec{u}-\frac{\vec{\nabla} P}{\rho}+\vec{g} .
$$

The magnitudes solved for are the fluid velocity $\vec{u}$ and the atmospheric pressure $P$. The fluid has a kinematic viscosity $v$ and its density is $\rho$. The gases are compressible and $\rho$ is modified by the combined effect of the temperature $T$ and pressure $P$. They are linked by the equation state of ideal gases

$$
P=n R T \text {. }
$$


$R$ is the molar gas constant $\sim 8.315 \mathrm{~J} /(\mathrm{K} \mathrm{mol})$ and $n$ is the molar density. The total fluid density $\rho$ and the fluid velocity $\vec{u}$ are linked by the mass transport equation

$$
\frac{\partial \rho}{\partial t}+\vec{\nabla}(\rho \vec{u}) \vec{u}=0
$$

The atmosphere of Earth is composed of nitrogen (78\%) and oxygen (21\%) mainly. Several other gases appear at a lower concentration (noble gases argon, neon, helium and krypton, carbon dioxide $\mathrm{CO}_{2}$, methane $\mathrm{NH}_{4}$ and water vapour). In this work, we are interested in the transport and diffusion of trace gases. For this purpose, we separated the gas phase into two components. The main component describes dry air with a mass density of $1.2 \mathrm{~kg} / \mathrm{m}^{3}$ at sea level and a trace component expelled from the vessel exhaust. For the trace component $\mathrm{CO}_{2}$ was chosen throughout the work. Within the ideal gas approximation, the behaviour of the trace gas is representative of other gas phase pollutants also.

The wind velocities were defined as the wind speed and direction in the upper part of the simulation domain. The speed values considered for this work ranged between $1 \mathrm{~m} / \mathrm{s}$ and $15 \mathrm{~m} / \mathrm{s}$. Four directions, north was $(0,1,0)$, were considered starting from $\hat{u}=(-1,1,0)$ and varying the orientation of the direction vector by $90^{\circ}$. The high Reynolds number $R e=u L / v \gg 1000$ corresponded to the turbulent regime. The $\kappa-\epsilon$ Reynolds Averaged Simulation (RAS) turbulence model [15] was used to describe the turbulence.

\subsection{Atmospheric Boundary Layer}

The simulation of an atmospheric air column required setting up carefully the boundary conditions of the circulating air. The wind flow along the computational domain was stabilized using the atmospheric boundary layer model developed by Richards and Norris [16] with the generalized formulation used by Hargreaves et al. [17] and Yang et al. [18]. The velocity is fixed and horizontal in the atmospheric boundaries with a vertical profile

$$
u_{A B L}(z)=\frac{U_{*}}{\kappa} \ln \left(\frac{z-z_{g}(x, y)+z_{0}}{z_{0}}\right) .
$$

$\kappa=0.41$ is the von Karman constant, $z_{g}(x, y)$ is the topographic ground height, the value of which at each point depends on the topographic height, and $z_{0}$ is a surface roughness coefficient that was set up to $5 \mathrm{~m}$ to match the buildings' height. The friction velocity $U_{*}$ is a reference value calculated as $U_{*}=\kappa u_{r e f} / \ln \left(\left(z_{\text {ref }}+z_{0}\right) / z_{0}\right)$. The velocity $u_{r e f}$ was chosen equal to the wind speed in the upper limit of the simulation domain.

For the temperature of the air at sea level $(z \sim 0 \mathrm{~m}) \mathrm{T}_{0}=0{ }^{\circ} \mathrm{C}, 10^{\circ} \mathrm{C}$ and $20^{\circ} \mathrm{C}$ were chosen. The temperature in the atmospheric lateral boundaries was fixed to a linear profile $T=T_{0}-0.01 z$. The turbulence model parameters were set up as

$$
\begin{array}{r}
k=\frac{U_{*}^{2}}{\sqrt{C_{\mu}}} \\
\epsilon=\frac{U_{*}^{3}}{\kappa\left(z-z_{g}(x, y)-z_{0}\right)}
\end{array}
$$

$C_{\mu}=0.09$ being the turbulent viscosity coefficient.

\subsection{Numerical Solutions}

The simulations were run using the OpenFOAM [19] CFD software based in the field operation and manipulation (FOAM) $\mathrm{C}++$ class library for continuum mechanics. OpenFOAM uses the finite volume numerical method to integrate the Navier-Stokes equation.

The simulated gas mixture is composed by atmospheric air and a trace component that in this simulation was identified with $\mathrm{CO}_{2}$. The trace gas was expelled by the docked vessel through its chimney. In the plume outlet, $40 \%$ of the outgoing gas mass corresponded to $\mathrm{CO}_{2}$. The $\mathrm{CO}_{2}$ fraction at each cell was updated every time step using the mass conservation 
equation (Equation (3)). Buoyancy effects were included and the thermodynamical model of the fluid takes included the enthalpy $h_{f}$ and the specific heat capacity $c_{p}$. The transport properties were described through the dynamic viscosity $\mu$ and the Prandtl number Pr. Their values for each component of the mixture are given in Table 1. The boundary conditions set for the simulations are listed in Table 2.

Table 1. Transport and thermodynamic parameters. All the values are given for $1 \mathrm{~atm}$ and $285 \mathrm{~K}$.

\begin{tabular}{lccc}
\hline & Air & $\mathbf{C O}_{2}$ & \\
\hline Viscosity $\mu$ & 17.9 & 13.7 & $\mu \mathrm{Pa} \cdot \mathrm{s}$ \\
Prandtl number $P r$ & 0.71 & 0.765 & - \\
Molar weight $n$ & 28.97 & 44.01 & $\mathrm{~g} / \mathrm{mol}$ \\
Specific heat capacity $c_{p}$ & 1005 & 846 & $\mathrm{~J} /(\mathrm{kg} \cdot \mathrm{K})$ \\
Enthalpy $h_{f}$ & 330 & 8647 & $\mathrm{~J} / \mathrm{kg}$ \\
\hline
\end{tabular}

Equations (1)-(3) are solved using a combination of the PISO (Pressure-Implicit with Splitting of Operators) algorithm [20] and the SIMPLE (Semi-Implicit Method for Pressure Linked Equations) algorithm [21]. This choice allows to increase the size of the time step to speed up the simulation. The transient simulation was run for $1000 \mathrm{~s}$ simulation time in parallel in 32 cores. The simulation time was chosen to ensure that the wind flow and the $\mathrm{CO}_{2}$ distribution reached a stationary state and it was short enough to disregard disturbances on the breeze circulation coming from tides and insolation.

The study addressed the effect of wind speeds and directions, atmospheric temperature, chimney height and exhaust gas temperature. Wind speed and directions cover the most usual atmospheric conditions in the city of Tromsø. On the other hand, chimney height and exhaust gas temperature describe the most important variables of the exhaust emission. The values chosen for the parameter study are given in Table 3.

Table 2. Boundary conditions. All the boundary conditions used are detailed. The solver solves the quantity $P-\rho g z$ instead of the total atmospheric pressure. Its boundary value is set up so that the gradient matches the velocity boundary condition.

\begin{tabular}{ll}
\hline & Boundary Conditions \\
\hline$P-\rho(z) g z$ & Fixed flux \\
$\rho, \mathrm{Y}_{\mathrm{CO}_{2}}$ & Zero gradient \\
& Top boundary \\
\hline$\vec{u}$ & Fixed uniform (ABL) \\
$k, \epsilon, T$ & Zero gradient \\
& Side boundaries \\
\hline$\vec{u}, k, \epsilon$ & Fixed non-uniform $(\mathrm{ABL})$ \\
$T$ & Fixed non-uniform $(-0.01 \mathrm{~K} / \mathrm{m})$ \\
& Ground \\
\hline$\vec{u}$ & Non-slip \\
$T$ & Zero gradient \\
$k, \epsilon$ & Wall function \\
& Exhaust \\
\hline$\vec{u}$ & Fixed value (25 $\mathrm{m} / \mathrm{s} \hat{z})$ \\
$T$ & Total temperature \\
$k$ & Turbulent intensity $(0.05)$ \\
$\epsilon$ & Turbulent mixing length $(50 \mathrm{~m})$ \\
\hline
\end{tabular}


Table 3. Simulation parameters. The parameters of the studies and their values are given. The highlighted values are the parameter values for the reference case.

\begin{tabular}{lll}
\hline Wind speed & $u$ & $1,3, \mathbf{5}, 15 \mathrm{~m} / \mathrm{s}$ \\
Wind direction & $\hat{u}$ & $\mathrm{NW}(-\mathbf{1}, \mathbf{1}, \mathbf{0}), \mathrm{NE}(1,1,0), \mathrm{SE}(1,-1,0), \mathrm{SW}(-1,-1,0)$ \\
Ambient temperature & $T_{0}$ & $0^{\circ}, \mathbf{1 0}^{\circ}, 20^{\circ} \mathrm{C}$ \\
Chimney height & $h_{c}$ & $5, \mathbf{1 0}, 20 \mathrm{~m}$ \\
Exhaust temperature & $T_{c}$ & $10^{\circ}, \mathbf{1 1 0}^{\circ}, 200^{\circ} \mathrm{C}$ \\
\hline
\end{tabular}

\section{Results}

The simulation of the atmospheric boundary layer poses a challenge for CFD. The main problem lies in the inherently turbulent nature of the atmospheric flow and cloud formation, further complicated by the orography of the terrain and the buildings [22,23]. A realistic wind flow requires taking into account many details like changes in transport properties with temperature and pressure, as well as the boundary conditions in contact with the terrain or in the top of the simulation domain. The thermodynamical properties of the gas mixture composing the air has also to account for the heat transfer properties with diverse heat sources, the solar insolation or the content of water vapour.

When the simulation is performed for stable atmospheric conditions and it is constrained to the lower part of the atmospheric boundary layer, the surface layer, a stable wind flow can be obtained using a $k-\epsilon$ turbulence model [24] and by setting the boundary conditions proposed by Richard and Hoxey [16] for the velocity, the pressure as well as the turbulent kinetic energy $k$ and its dissipation rate $\epsilon$.

Between the lower and the upper boundary of the simulation domain the thermodynamical quantities vary by only $3.5 \%$ for the pressure, $1 \%$ for the temperature and $2.5 \%$ for the molar density $n$ of an ideal gas. The narrow thermodynamical conditions allow using a constant value of the transport and thermodynamic properties.

In contrast, the simplifying assumption of incompressibility cannot be applied to atmospheric gas. The equation of state for the perfect gas was used to connect the pressure to the thermodynamical properties of the fluid (temperature, enthalpy and specific heat capacity) as well as the mass density. The relevant parameters are given in Table 1. To ensure a stable run, an appropriate choice of boundary conditions and initial conditions is crucial. To constrain $\vec{U}$ and the turbulence model parameters $(k, \epsilon)$ in the lateral boundaries the ABL condition was used. The ABL values correspond to a stable dry atmosphere with a defined wind flow at heights well above the orographic obstacles. The temperature was constrained to be equal to $T_{0}$ at ground level and had a vertical gradient of $-0.01 \mathrm{~K} / \mathrm{m}$. At the top boundary, all quantities had zero gradient boundary conditions, except for $\vec{U}$ which had a fixed value corresponding to the free wind flow. On the bottom boundary, no slip condition was used for $\vec{U}$ and wall functions for the turbulence parameters. The rest of the magnitudes had zero gradient conditions.

\subsection{Simulation Run}

In a first step, the simulation is run for $100 \mathrm{~s}$ without exhaust gas to let the wind flow stabilize; the resulting velocity distribution is shown in Figure 3a). In the upper part of the simulation domain the velocity field was parallel to the general wind flow. Closer to the ground, the wind flow was disturbed by the orography and the city buildings. In a second step, the simulation was run with the outflow from the exhaust included for at least $500 \mathrm{~s}$ so that the new air flow reached a stationary regime. The atmospheric wind flow was then disturbed by the ascending air $+\mathrm{CO}_{2}$ plume, see Figure 3b). The dynamic pressure, $P-\rho g z$, shows the low pressure zone created by the plume on the general air flow. $\mathrm{CO}_{2}$ gas was transported upwards by the fast outgoing plume and subsequently drifted following the general wind flow. At the same time, sidewards from the plume an outdiffusion of the pollutant occurred. Part of it reached the ground level where an excess of $\mathrm{CO}_{2}$ could be built. The pollutant excess is defined as a $10 \%$ excess over the background level of $\sim 400 \mathrm{ppm}$. This happened mainly right below the plume except for the width of 
the excess area, and its downwind size was modified by the local orography and buildings, but also other factors. To study the influence of other factors a series of parameter studies were performed.

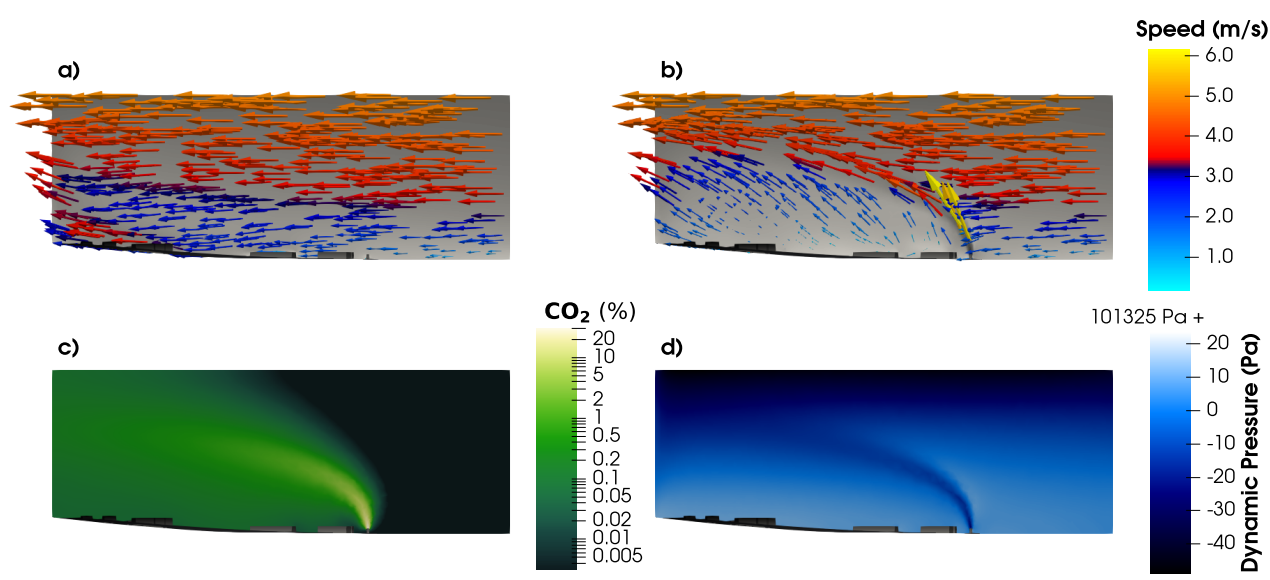

Figure 3. Simulation overview. Slice of the simulation domain parallel to the main wind flow, north-west $(-1,1,0)$, cut through the middle of the plume. The chimney is $10 \mathrm{~m} \mathrm{high}, \mathrm{T}_{0}=10^{\circ} \mathrm{C}$, $T_{c}=110{ }^{\circ} \mathrm{C}$ and wind speed $5 \mathrm{~m} / \mathrm{s}$. The velocity values (a) before the plume sets on and (b) after. The (c) concentration of $\mathrm{CO}_{2}$ is given as percentages of the total mass. The (d) dynamic pressure $P-\rho g z$ is also shown.

\subsection{Wind Direction}

To study the concentration of $\mathrm{CO}_{2}$ depending on the incoming wind direction, the direction of the wind was modified for an incoming wind speed of $5 \mathrm{~m} / \mathrm{s}$. The chimney height was kept $10 \mathrm{~m}$ high, the temperature of the plume $T_{\mathcal{C}}=110^{\circ} \mathrm{C}$ and the ambient temperature $10^{\circ} \mathrm{C}$.

The dominant local winds blow parallel to the coast along the north-east direction. In addition, the breeze circulation can add a component perpendicular to the coast. Therefore, the four chosen directions blow towards inland, approximately north-west or $(-1,1,0)$ wind, parallel to the coast, north-east or $(1,1,0)$ and south-west $(-1,-1,0)$ winds, and towards the sea, south-east $(1,-1,0)$ wind (see Figure 4$)$.
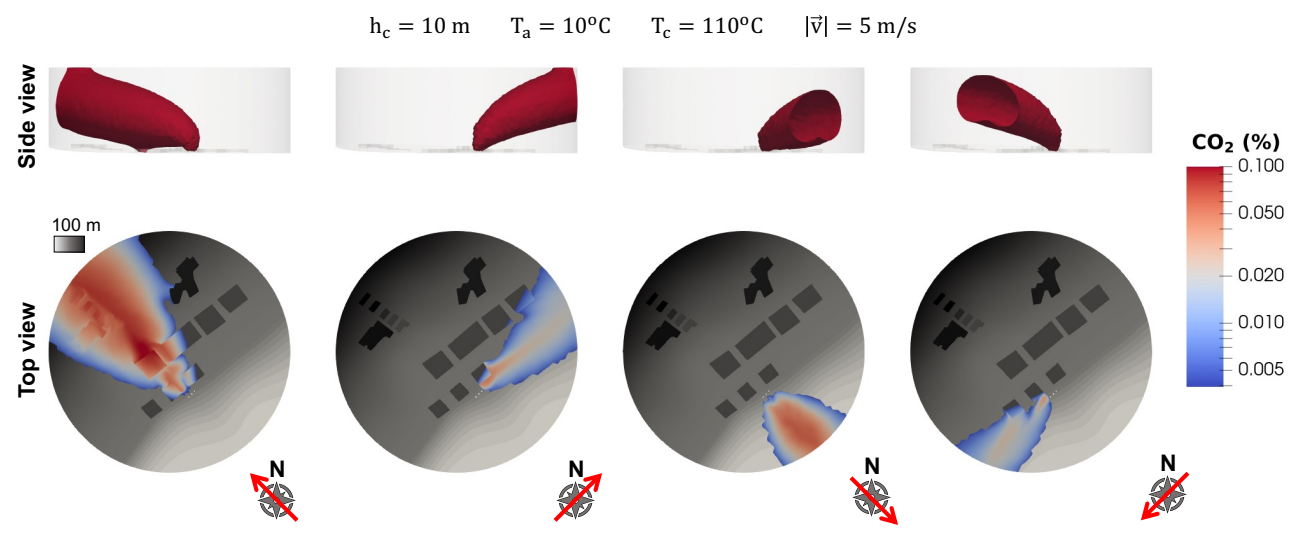

Figure 4. Wind direction. Concentration of $\mathrm{CO}_{2}$ at ground level for wind speed $\mathrm{u}=5 \mathrm{~m} / \mathrm{s}$. The wind direction is represented by a red arrow. The chimney height is $10 \mathrm{~m}$, the ambient temperature $10^{\circ}$ and the exhaust gas temperature is $110^{\circ} \mathrm{C}$ in all cases. The terrain height is represented in a grayscale. Lighter colors correspond to lower heights and the sea has the lightest color. The chimneys are three white spots near the coastline. The upper panels, show the concentration of $\mathrm{CO}_{2}$ within the plume. The $0.1 \%, 1000 \mathrm{ppm}$, surface for $\mathrm{CO}_{2}$ was plotted in all cases. 
The concentration of $\mathrm{CO}_{2}$ in the city only increases when the wind blows inland, north-west. The wind blowing in the opposite direction, towards the sea or south-east, also deposit pollutant gas on the sea. In both directions, the gentle slope of the terrain near the sea increases the deposition rate both inland and on the sea. In line with this, the winds blowing parallel to the coast, north-east and south-west, yield a much lower deposition of the pollutant. The main reason for this is that the exhaust plume travels upward higher.

\subsection{Wind Speed}

The speed of the incoming flow is a determining factor in the range of dispersion of the pollutant. In general the largest concentration at ground level is always detected right below the plume. However, the sidewards distribution and the peak concentration value of the deposited gas molecules can vary remarkably. The widest distribution of excess pollutant is obtained for the lowest wind speed. While the highest concentration is reached downwind, the concentration sideways remains high in the whole simulation domain. In addition, there is also a noticiable deposition of pollutant upwind. For a medium value, $5 \mathrm{~m} / \mathrm{s}$, and the highest value, $15 \mathrm{~m} / \mathrm{s}$, the gas deposition remains detectable in narrower areas. It has a width of $\sim 120 \mathrm{~m}$ in the first case and $\sim 200 \mathrm{~m}$ in the second at the maximum deposition concentration distance from the chimneys.

The case with wind speed of $3 \mathrm{~m} / \mathrm{s}$ is different from the rest in the fact that the deposition of the pollutant is lower by an order of magnitude. This anomaly is better understood by noting that the plume, see the side view in Figure 5, flows higher and therefore less pollutant reaches the ground. Larger wind speeds increase the drag of the gas molecules away from the chimney diminishing the time for lateral dispersion. This effect is the main reason why the concentration of pollutant is radically smaller when going from wind speeds of $1 \mathrm{~m} / \mathrm{s}$ to $3 \mathrm{~m} / \mathrm{s}$. At larger wind speeds, the maximum height reached by the plume is shortened by the stronger pull exerted by the main wind flow. The interplay between these factors, the first being dominant for low wind speeds and the latter for wind speeds above $5 \mathrm{~m} / \mathrm{s}$, explains the observed trend.
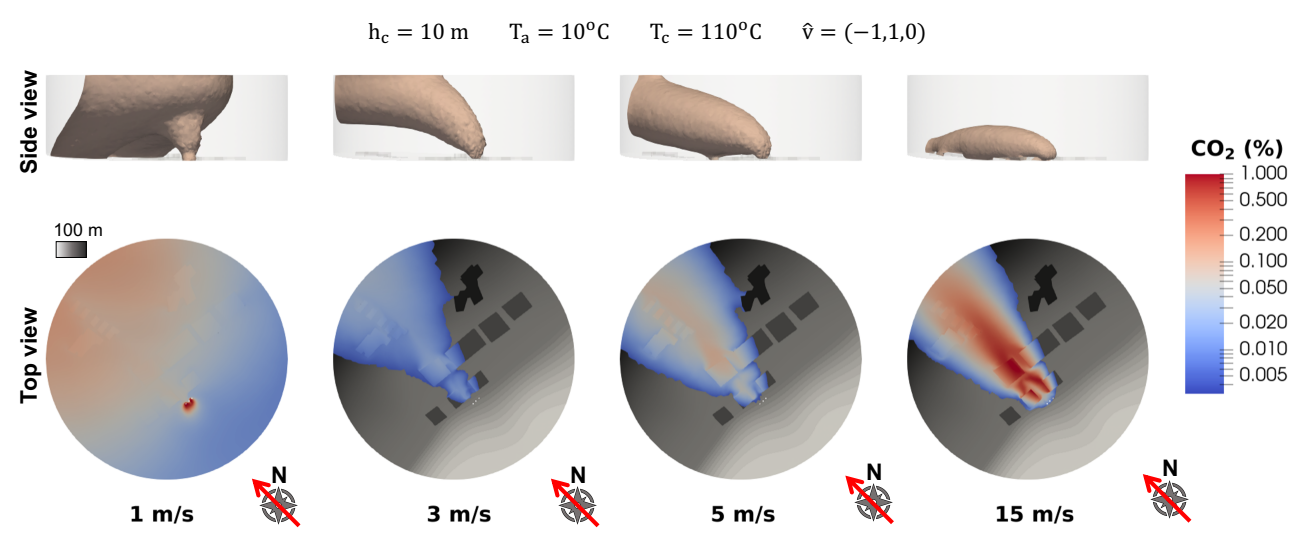

Figure 5. Wind speed. Concentration of $\mathrm{CO}_{2}$ at ground level for inland north-west wind, $(-1,1,0)$. The chimney height is $10 \mathrm{~m}$, the ambient temperature is $10^{\circ} \mathrm{C}$ and the exhaust gas temperature $110^{\circ} \mathrm{C}$ in all cases. The terrain height is represented in a grayscale. Lighter colors correspond to lower heights and the sea has the lightest color. The chimneys are three white spots near the coastline. The upper panels show the $\mathrm{CO}_{2}$ concentration isosurfaces $(0.1 \%, 1000 \mathrm{ppm})$ representing the plume distribution within the simulation domain.

\subsection{Temperature of the Plume}

Another important factor determining the final distribution of $\mathrm{CO}_{2}$ in the ground is the temperature of the outflowing gas at the chimney exit. Higher outflow temperature enhances the upwards buoyancy of the exhaust gas due to its lower density. In contrast, at lower temperatures the exhaust gas will get dragged downwards. When the temperature of the exhaust gas is equal to the ambient temperature $T_{\mathcal{C}}=10^{\circ} \mathrm{C}$, see Figure 6 , the amount of 
deposited pollutant is strongly enhanced. When the exhaust gas temperature is $T_{c}=210^{\circ} \mathrm{C}$ the concentration decreases by 2 orders of magnitude and the side range of the deposited gas decreases to less than half.
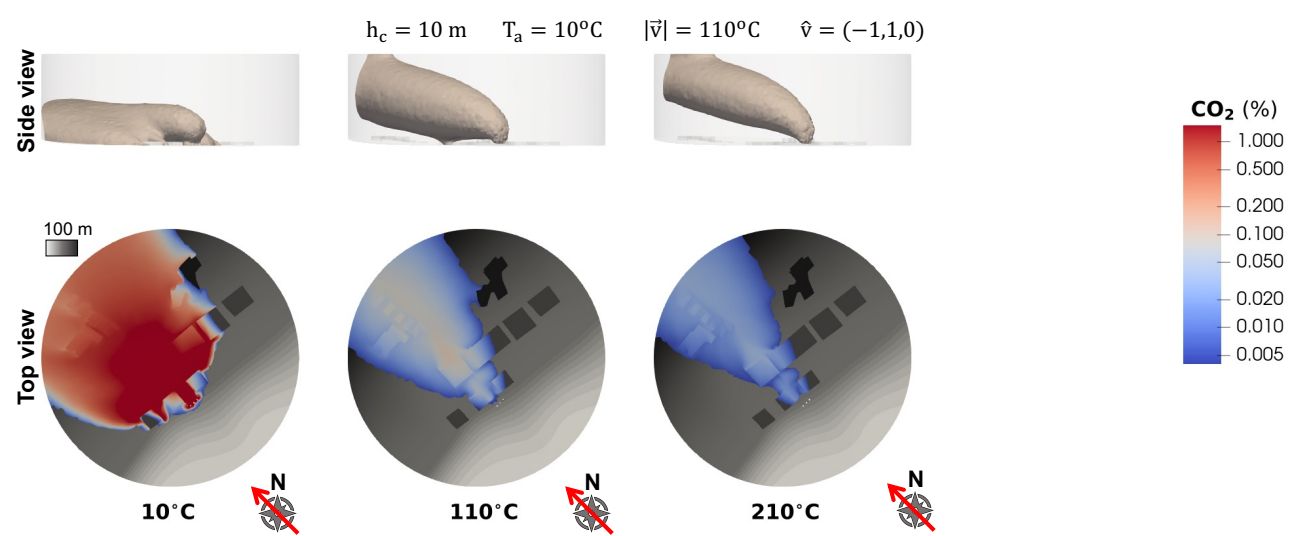

Figure 6. Exhaust gas Temperature. Concentration of $\mathrm{CO}_{2}$ at ground level for wind speed $u=5 \mathrm{~m} / \mathrm{s}$ and north-west $(-1,1,0)$ direction. The chimney height is $10 \mathrm{~m}$ and the ambient temperature $10{ }^{\circ} \mathrm{C}$ in all cases. The terrain height is represented in a grayscale. Lighter colors correspond to lower heights and the sea has the lightest color. The chimneys are three white spots near the coastline. The upper panels, show the concentration of $\mathrm{CO}_{2}$ within the plume. The $0.1 \%, 1000 \mathrm{ppm}$, surface for $\mathrm{CO}_{2}$ was plotted in all cases.

\subsection{Chimney Height}

The chimney height (see Figure 7) has a negligible effect on the deposited gas within the simulated area. Moreover, the ambient temperature, shown in Figure 8, has a small effect on the deposited pollutant. In all cases, the region where a significant deposition of $\mathrm{CO}_{2}$ is observed remains largely unchanged and the concentration of the deposited pollutant is also similar.
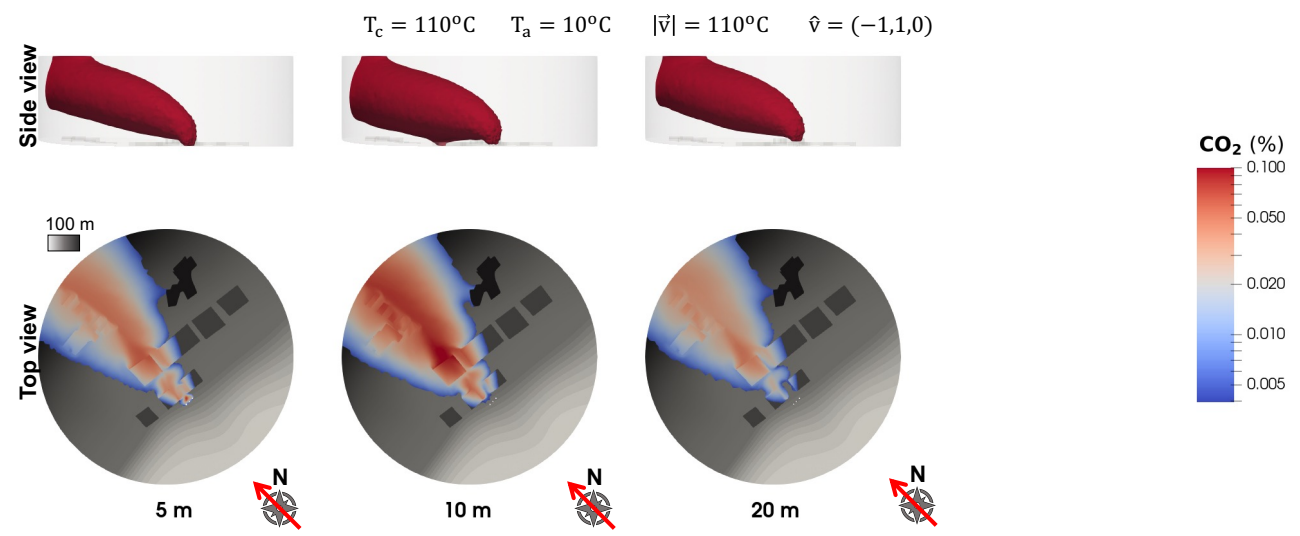

Figure 7. Chimney height. Concentration of $\mathrm{CO}_{2}$ at ground level for wind speed $u=5 \mathrm{~m} / \mathrm{s}$ and north-west $(-1,1,0)$ direction. The ambient temperature is $10{ }^{\circ} \mathrm{C}$ and the exhaust gas temperature $110{ }^{\circ} \mathrm{C}$ in all cases. The terrain height is represented in a grayscale. Lighter colors correspond to lower heights and the sea has the lightest color. The chimneys are three white spots near the coastline. The upper panels show the concentration of $\mathrm{CO}_{2}$ within the plume. The $0.1 \%, 1000 \mathrm{ppm}$, surface for $\mathrm{CO}_{2}$ was plotted in all cases. 

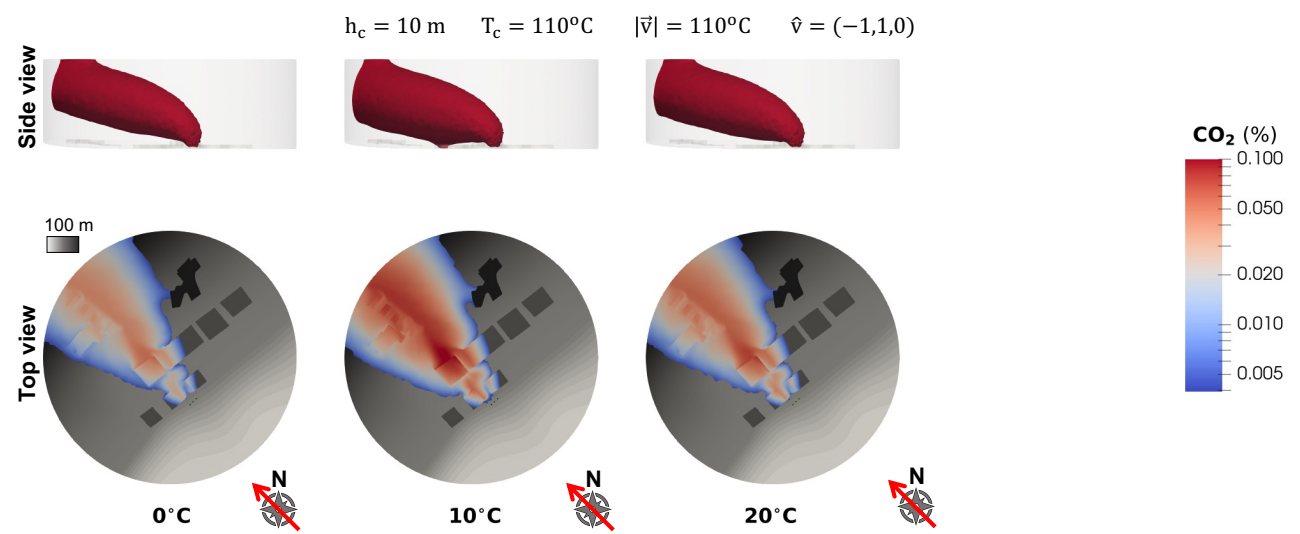

Figure 8. Ambient Temperature. Concentration of $\mathrm{CO}_{2}$ at ground level for wind speed $u=5 \mathrm{~m} / \mathrm{s}$ and north-west $(-1,1,0)$ direction. The chimney height is $10 \mathrm{~m}$ and the exhaust gas temperature $110{ }^{\circ} \mathrm{C}$ in all cases. The terrain height is represented in a grayscale. Lighter colors correspond to lower heights and the sea has the lightest color. The chimneys are three white spots near the coastline. The upper panels, show the concentration of $\mathrm{CO}_{2}$ within the plume. The $0.1 \%, 1000 \mathrm{ppm}$, surface for $\mathrm{CO}_{2}$ was plotted in all cases.

\section{Discussion}

The wind blowing directly inland, north-west $(-1,1,0)$, is found to be the most relevant to understand the transport of gas phase pollutants into the city. In all cases, the deposition of $\mathrm{CO}_{2}$ is the largest right below the center of the plume. When the wind speed is very low the concentration downwind stays relatively constant within the simulated domain, as can be seen in Figure 9. The drag of the main wind flow is low and the pollutant disperses mostly by diffusion. It must be noted that the concentration upwind has a sharp maximum near the chimney and decays fast at larger distances as shown in Figure 5. For slightly larger wind speeds, the deposited gas increases up to a distance of around $200 \mathrm{~m}$. At longer distances it remains roughly constant until the boundary of the simulation domain. When the wind speed is $5 \mathrm{~m} / \mathrm{s}$ or higher, the pollutant still has a peak concentration, but at longer distances from the chimney, the concentration of pollutant decreases, especially for the largest wind flow speed. The peak $\mathrm{CO}_{2}$ concentration is the lowest at moderate speeds, $3 \mathrm{~m} / \mathrm{s}$, and increases steadily as the wind speed increases.
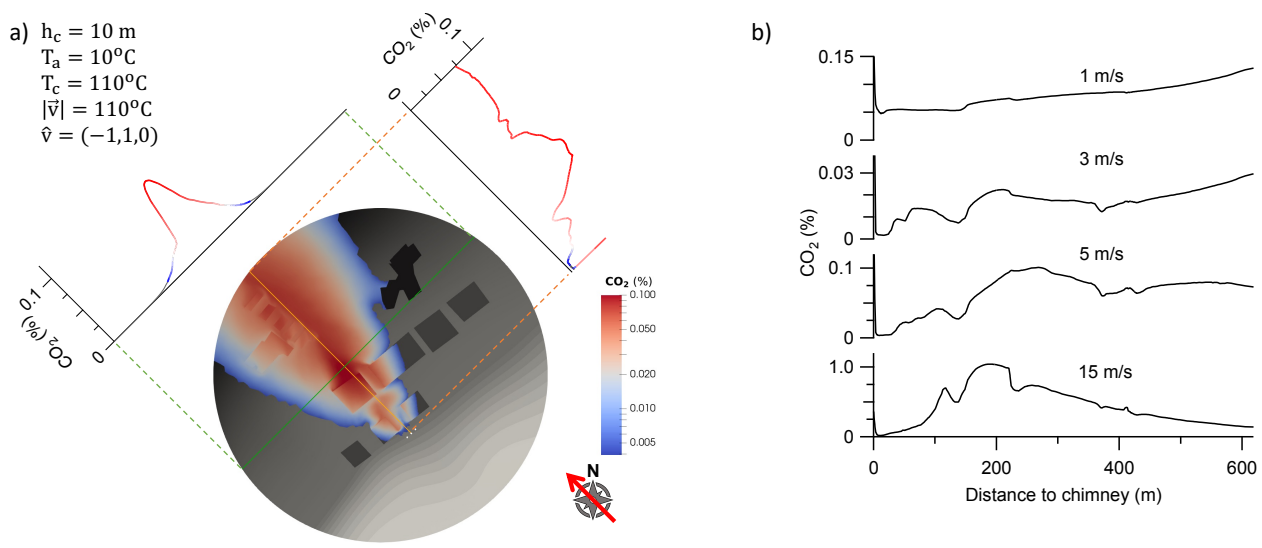

Figure 9. $\mathrm{CO}_{2}$ concentration sections at ground level. Panel (a) shows the line distribution of $\mathrm{CO}_{2}$ parallel to the main wind flow of $5 \mathrm{~m} / \mathrm{s}$ (orange line) below the center of the plume where the concentration is the highest. A line distribution crossing the plume perpendicular to the wind flow along the highest concentration (green line) is also shown. The concentration distribution around the center is approximately gaussian. Panel (b) shows the $\mathrm{CO}_{2}$ distribution downwind for 1, 3, 5 and $15 \mathrm{~m} / \mathrm{s}$ wind speeds. The wind blows in the north-west $(-1,1,0)$ direction. The chimney is $10 \mathrm{~m}$ high and the gas has $110^{\circ} \mathrm{C}$ at the exit of the plume. The ambient temperature is $10^{\circ} \mathrm{C}$. 
The lateral distribution is the widest at very low speed due to the weak drag. At moderate speeds it decreases sharply due to the low deposition rate and at speeds of $5 \mathrm{~m} / \mathrm{s}$ it takes a triangular shape and a size that remains largely unchanged. The wind speed, chimney height, plume temperature and ambient temperature have little effect on the lateral width of the deposition range. The wind direction has a larger influence mainly due to the local disturbance of the general wind flow driven by the orography and the city buildings, as Figure 10 shows in detail. Winds with a downhill or uphill direction are seen to provoke a larger deposition of gas pollutants. On the other hand, for winds blowing the plume in flat regions, the upwards buoyancy effect is enhanced by the wind flow largely parallel to the ground.

Inside the city, localized pockets with high concentration of pollutants can be created which can have a negative influence in the air quality. An example can be seen in the third and fourth panels of Figure 5. This effect is more apparent close to the emission point, or around $200 \mathrm{~m}$ for the conditions of this work. Another important factor is the plume temperature. The deposition is enhanced when the plume has a temperature close to the ambient temperature, which can have technological implications when low emission temperatures reflect lower working temperature conditions of the engine of the vessel. Engines working at lower temperature can increase its energy efficiency, but the impact of the pollutants expelled in the plume is larger in the surrounding areas. Therefore, it would require a more careful treatment of the exhaust gas.

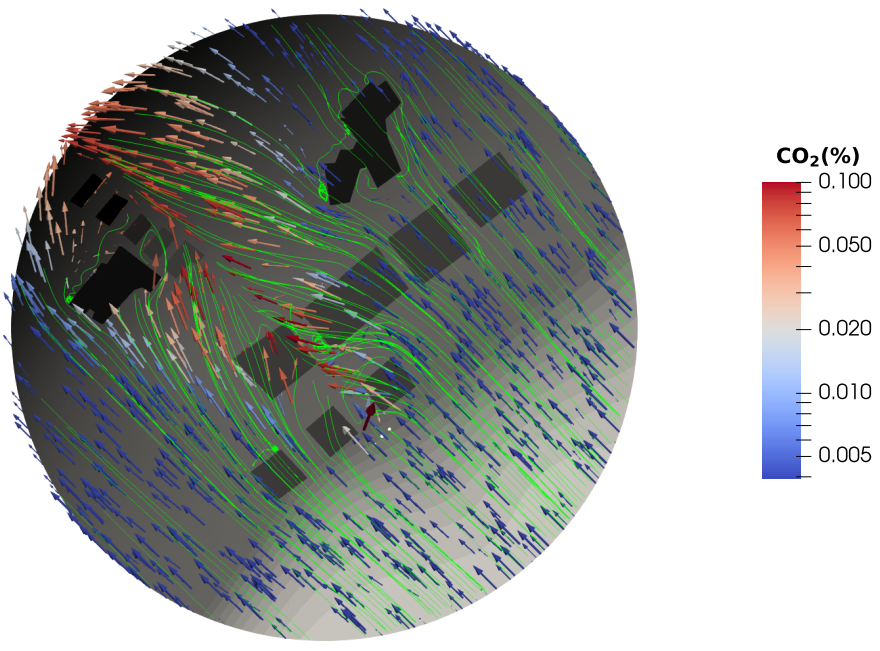

Figure 10. Air circulation at street level. The streamlines (green) represent the wind path around the buildings. The vectors give the wind speed and direction at each point. The colors of the vectors follow the $\mathrm{CO}_{2}$ distribution. The wind blows in the north-west $(-1,1,0)$ direction. The chimney is $10 \mathrm{~m}$ high and the gas has $110^{\circ} \mathrm{C}$ at the exit of the plume. The ambient temperature is $10^{\circ} \mathrm{C}$.

A point that future works need to address is the effect of pollutant gases other than $\mathrm{CO}_{2}$. Given that pollutants tend to have a larger molecular mass than clean air, their distributions are expected to mirror the distribution of $\mathrm{CO}_{2}$, which also has larger molecular mass. The general trends observed for $\mathrm{CO}_{2}$ should also be valid for other pollutants. However, the typical concentration of pollutants at the emission point is normally lower than assumed in this work. This will decrease the peak deposited amount of pollutant and can decrease the lateral range of the deposited pollutant. A detailed discussion of the effects of other pollutants and, especially, particulate matter would require a follow-up work where the composition of the exhaust gas is varied. The simulation domain should also be enlarged downwind to find the deposition range along the wind axis direction. In like manner, studying the deposition of particulate matter would require a larger simulation domain downwind. 


\section{Conclusions}

An accurate CFD model of the harbour area of Tromsø was built in order to model the deposition of $\mathrm{CO}_{2}$ gas emitted by docked vessels within the city. It includes buoyancy and fluid compressibility effects as well as the thermodynamics of perfect gases. Stabilization of the general wind flow was achieved by forcing the atmospheric boundary layer conditions in the lateral boundaries of the domain. The diffusion of $\mathrm{CO}_{2}$ out of the plume into the surrounding air is also modelled and it is found to have noticeable effects, especially at low wind speeds. The influence of the wind speed and direction, vessel chimney height, ambient temperature and exhaust gas temperature were studied. The wind direction, as expected, determined the direction where the pollutant gas will be deposited. More interesting is the trend found when varying the wind speed blowing inland. The deposition range was the largest when the wind speed was very low. In this case the diffusion effects dominate over the transport effects and the pollutant gas has a wide distribution range extending several hundred meters downwind and in a lateral direction. At moderate speeds, the plume is transported far from the city area before the deposition happens. Interestingly, at even larger speeds, the height of the plume is shortened increasing the deposition below the plume. The lateral distribution is $100-200 \mathrm{~m}$ wide in most cases. The simulations show that the interplay between the main wind flow, the local orography and the city buildings can create pockets of high pollutant concentration.

This simulation model can be extended to study other types of pollutants or particulate matter. They can be of high interest for a detailed study of the contamination in cities near coasts or an industrial pollutant source. A next step to increase the accuracy of this model would be validation of the results using field data.

Author Contributions: Conceptualization, A.Z., H.K. and G.B.; methodology, A.Z.; software, A.Z.; formal analysis, A.Z.; investigation, A.Z.; resources, S.M.; data curation, S.M.; writing-original draft preparation, A.Z.; writing-review and editing, A.Z., S.M., H.K. and G.B.; visualization, A.Z.; project administration, H.K. and G.B.; funding acquisition, H.K. and G.B. All authors have read and agreed to the published version of the manuscript.

Funding: This research received no external funding. The APC was funded by the Zurich University of Applied Sciences (ZHAW).

Conflicts of Interest: The authors declare no conflict of interest. The funders had no role in the design of the study; in the collection, analyses, or interpretation of data; in the writing of the manuscript, or in the decision to publish the results

\section{References}

1. Kim, K.H.; Kabir, E.; Kabir, S. A review on the human health impact of airborne particulate matter. Environ. Int. 2015, 74, 136-143. [CrossRef] [PubMed]

2. Davidson, C.I.; Phalen, R.F.; Solomon, P.A. Airborne Particulate Matter and Human Health: A Review. Aerosol Sci. Technol. 2005, 39, 737-749. [CrossRef]

3. Roskilly, A.P.; Nanda, S.K.; Wang, Y.D.; Chirkowski, J. The performance and the gaseous emissions of two small marine craft diesel engines fuelled with biodiesel. Appl. Therm. Eng. 2008, 28, 872-880. [CrossRef]

4. Walter, R.A.; Broderick, A.J.; Sturm, J.C.; Klaubert, E.C. USCG Pollution Abatement Program: A Preliminary Study of Vessel and Boat Exhaust Emissions; Report Number DOT-TSC-USCG-72-3; United States Coast Guard: Washington, DC, USA; John A. Volpe National Transportation Systems Center: Cambridge, MA, USA, 1971,

5. Simeone, L.F. The Intrusion of Engine Exhaust into the Passenger Areas of Recreational Power Boats; Report Number 227783325; United States Coast Guard: Washington, DC, USA; John A. Volpe National Transportation Systems Center: Cambridge, MA, USA, 1991.

6. Bentz, A.P.; Weaver, E. Marine Diesel Exhaust Emissions Measured by Portable Instruments. SAE Trans. 1994, $103,1872-1876$.

7. Johansson, L.; Ytreberg, E.; Jalkanen, J.P.; Fridell, E.; Eriksson, K.M.; Lagerström, M.; Maljutenko, I.; Raudsepp, U.; Fischer, V.; Roth, E. Model for leisure boat activities and emissions-Implementation for the Baltic Sea. Ocean Sci. 2020, 16, $1143-1163$. [CrossRef]

8. H. M. A. Schleijpen.; Filip P. Neele. Ship exhaust gas plume cooling. In Targets and Backgrounds X: Characterization and Representation. 2004, 5431, 66-76. [CrossRef]

9. Garcia-Gonzales, D.A.; Shamasunder, B.; Jerrett, M. Distance decay gradients in hazardous air pollution concentrations around oil and natural gas facilities in the city of Los Angeles: A pilot study. Environ. Res. 2019, 173, 232-236. [CrossRef] [PubMed] 
10. Ran, L.; Lin, W.L.; Deji, Y.Z.; La, B.; Tsering, P.M.; Xu, X.B.; Wang, W. Surface gas pollutants in Lhasa, a highland city of Tibet; current levels and pollution implications. Atmos. Chem. Phys. 2014, 14, 10721-10730. [CrossRef]

11. Zhang, R.; Wang, G.; Guo, S.; Zamora, M.L.; Ying, Q.; Lin, Y.; Wang, W.; Hu, M.; Wang, Y. Formation of Urban Fine Particulate Matter. Chem. Rev. 2015, 115, 3803-3855. [CrossRef] [PubMed]

12. Gorelick, N.; Hancher, M.; Dixon, M.; Ilyushchenko, S.; Thau, D.; Moore, R. Google Earth Engine: Planetary-scale geospatial analysis for everyone. Remote Sens. Environ. 2017, 202, 18-27. [CrossRef]

13. Solidworks ${ }^{\circledR}$ 26; Dassault Systèmes SolidWorks Corporation: Paris, France, 2018.

14. Ansys ${ }^{\circledR}$ Workbench 18; ANSYS Inc.: Canonsburg, PA, USA, 2018.

15. Launder, B.E.; Spalding, D.B. The numerical computation of turbulent flows. Comput. Methods Appl. Mech. Eng. 1974, 3, 269-289. [CrossRef]

16. Richards, P.J.; Hoxey, R.P. Appropriate boundary conditions for computational wind engineering models using the k- $\epsilon$ turbulence model. J. Wind. Eng. Ind. Aerodyn. 1993, 46-47, 145-153. [CrossRef]

17. Hargreaves, D.M.; Wright, N.G. On the use of the k- $\epsilon$ model in commercial CFD software to model the neutral atmospheric boundary layer. J. Wind. Eng. Ind. Aerodyn. 2007, 95, 355-369. [CrossRef]

18. Yang, Y.; Gu, M.; Chen, S.; Jin, X. New inflow boundary conditions for modelling the neutral equilibrium atmospheric boundary layer in computational wind engineering. J. Wind. Eng. Ind. Aerodyn. 2009, 97, 88-95. [CrossRef]

19. Weller, H.G.; Tabor, G.; Jasak, H.; Fureby, C. A tensorial approach to computational continuum mechanics using object-oriented techniques. Comput. Phys. 1998, 12, 620-631. [CrossRef]

20. Issa, R.I. Solution of the implicitly discretised fluid flow equations by operator-splitting. J. Comput. Phys. 1986, 62, 40-65. [CrossRef]

21. Caretto, L.S.; Gosman, A.D.; Patankar, S.V.; Spalding, D.B. Two calculation procedures for steady, three-dimensional flows with recirculation. In Proceedings of the Third International Conference on Numerical Methods in Fluid Mechanics; Lecture Notes in Physics; Cabannes, H., Temam, R., Eds.; Springer: Berlin/Heidelberg, Germany, 1973; pp. 60-68. [CrossRef]

22. Garratt, J.R. Review: the atmospheric boundary layer. Earth-Sci. Rev. 1994, 37, 89-134. [CrossRef]

23. Tran, V.; Ng, E.Y.K.; Skote, M. CFD simulation of dense gas dispersion in neutral atmospheric boundary layer with OpenFOAM. Meteorol. Atmos. Phys. 2019. [CrossRef]

24. Richards, P.J.; Norris, S.E. Appropriate boundary conditions for computational wind engineering models revisited. J. Wind. Eng. Ind. Aerodyn. 2011, 99, 257-266. [CrossRef] 